Article

\title{
Blue-Green Solutions and Everyday Ethicalities: Affordances and Matters of Concern in Augustenborg, Malmö
}

\author{
Misagh Mottaghi *, Mattias Kärrholm and Catharina Sternudd \\ Department of Architecture and the Built Environment, Lund University, 22100 Lund, Sweden; \\ E-Mails: misagh.mottaghi@arkitektur.lth.se (M.M.), mattias.karrholm@arkitektur.lth.se (M.K.), \\ catharina.sternudd@abm.Ith.se (C.S.)
}

* Corresponding author

Submitted: 26 May 2020 | Accepted: 13 July 2020 | Published: 12 November 2020

\begin{abstract}
This article aims to understand how the introduction of blue-green solutions affects ethical concerns and expectations of an urban environment. Blue-green solutions are complementary technical solutions, introduced into urban water management, in order to deal with the impact of urbanisation and climate change. These kinds of solutions establish new affordances that have an impact on everyday life in the urban environment. This article describes how blue-green solutions become part of urban settings and how they influence the inhabitant's perceptions, desires and matters of care concerning these settings. The article examines the interplay between blue-green technologies and the social, material and cultural context in the Augustenborg district in Malmö, Sweden. The study is based on the analysis of free-text answers to a questionnaire aimed to collect information about the interaction between blue-green solutions and everyday life in public spaces. By exploring the inhabitants' point of view, the article then seeks to recognise the meanings and thoughts entangled with place concerning different types of blue-green solutions. We summarise the main concerns raised by the inhabitants and discuss how the implementation of blue-green solutions relates to the transformation of everyday ethicalities and matters of concern relating to the neighbourhood. We conclude that blue-green infrastructure seems to come with a new kind of sensitivity, as well as with an intensification of concerns, in an existing urban environment. This has important social repercussions, which also makes it important to study the social role and implications of blue-green technologies further.
\end{abstract}

\section{Keywords}

affordance; blue-green solutions; ethicality; everyday life; public space; urban design; urban infrastructure; urban water management

\section{Issue}

This article is part of the issue "Built Environment, Ethics and Everyday Life" edited by Mattias Kärrholm (Lund University, Sweden) and Sandra Kopljar (Lund University, Sweden).

(C) 2020 by the authors; licensee Cogitatio (Lisbon, Portugal). This article is licensed under a Creative Commons Attribution 4.0 International License (CC BY).

\section{Introduction}

The climate is changing and intensive and frequent rainfalls have turned urban flood management into a growing concern in urban areas (Intergovernmental Panel on Climate Change, 2014). Underground pipe facilities are in many cases insufficient to manage urban stormwater and developing the drainage systems through surface open solutions in outdoor envi- ronments has become essential (i.e., Chocat, Krebs, Marsalek, Rauch, \& Schilling, 2001). The solutions have been termed and applied differently based on their local shared understanding (i.e., nature-based solutions, low impact development, water sensitive urban design, sustainable urban drainage systems and best management practices; Fletcher et al., 2015). In recent literature, there has been a broader interest in the term blue-green infrastructure (Stovin \& Ashley, 2019). 
The urban population is increasing dramatically, which exposes larger numbers of people to the risk of urban flooding (Kazmierczak \& Cavan, 2011). By 2050, $68 \%$ of the global population will reside in urban areas (United Nations, 2019). Urban areas are also getting denser. A larger proportion of constructed land and sealed surfaces make it difficult to leave surfaces open for flood management. Also, land use competition for different kinds of urban infrastructures seems to be going on, struggling for every free square meter of existing open space. This highlights the need for flexibility and multi-functionality of urban space (Mottaghi, Aspegren, \& Jönsson, 2016). However, for blue-green infrastructure to hydraulically perform, imposing changes on the urban landscape (e.g., modifying the urban setting, topography, type of vegetation and soil condition) is unavoidable (Backhaus \& Fryd, 2013). Further, making these changes influences the use of urban areas for different users, and increasing our knowledge on the use aspects is nec- essary for better integration with urban spaces in the future. While previous research has mostly focused on hydrological efficiency, adaptability and spatial morphology of blue-green infrastructure (i.e., Ashley et al., 2018; Bacchin, 2015; Haghighatafshar, 2019; Radhakrishnan, Pathirana, Ashley, Gersonius, \& Zevenbergen, 2018), knowledge about social dimensions remains quite vague and needs to be developed further (Ashley, Gersonius, \& Horton, 2020; Gandy, 2014). A variety of different values can be recognised as important for blue-green infrastructure, and these vary between different stakeholders. Non-technical and intangible values need to be better studied and understood to be taken into account in the early stages of planning (Vierikko \& Niemelä, 2016).

In this article, we use affordance theory to explore possibilities of use and the consequences of the implementation of open stormwater facilities in Augustenborg, an urban district in Malmö, Sweden (Figure 1). Augustenborg's outdoor environment was transformed

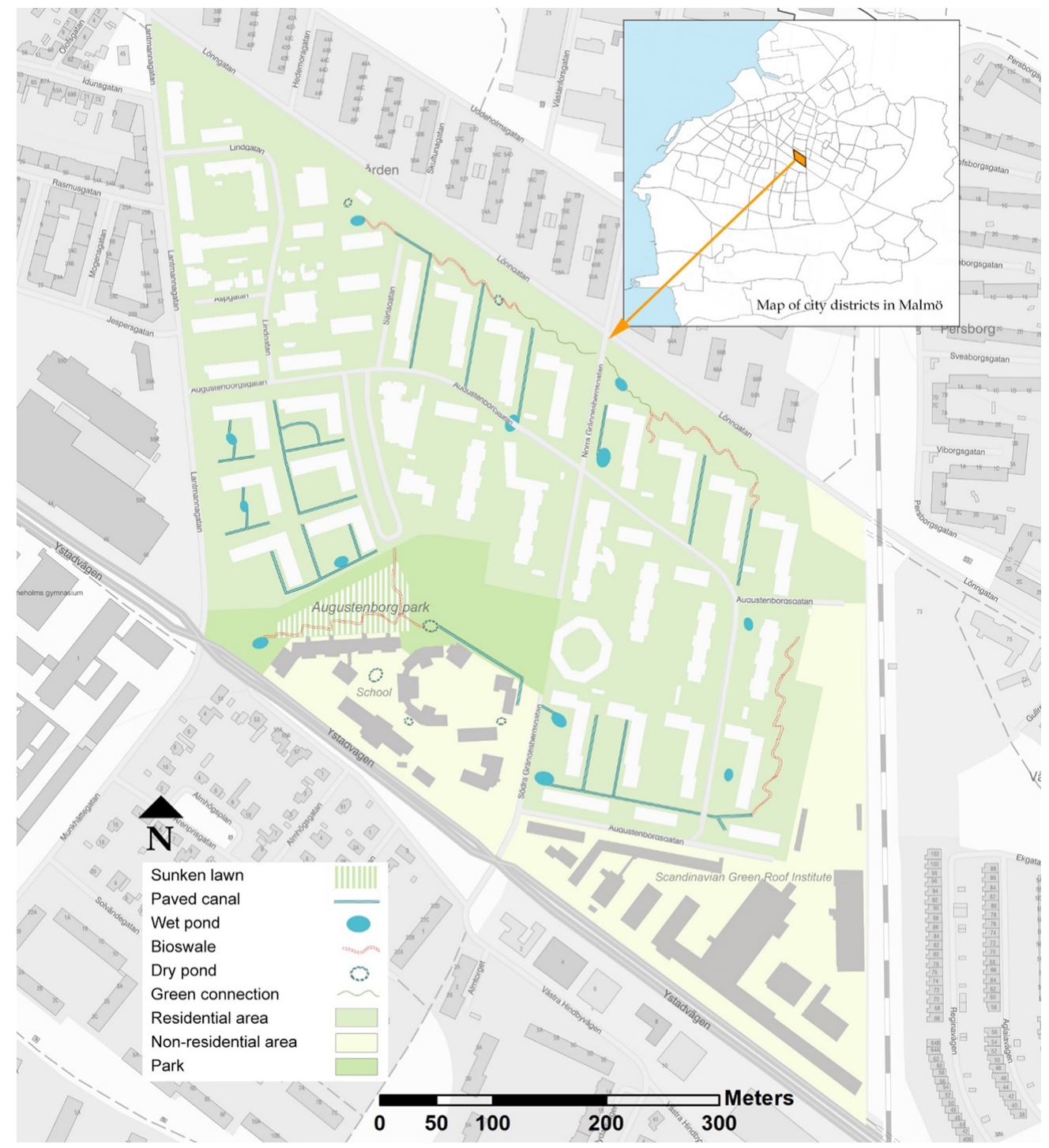

Figure 1. Map of Augustenborg showing blue-green solutions in public open spaces. Source: Misagh Mottaghi (the background picture is a topographic web map, courtesy of The Swedish Mapping, Cadastral and Land Registration Authority). 
into a flood resilient district through the implementation of surface drainage technologies between 1999 and 2003. It is a pioneer case of urban retrofitted projects in Europe and was chosen because everyday life has had enough time to adapt to these technologies. In this article, we provide an overview of how these facilities mediate human exchanges with the outdoor environment, with a specific focus on how they create possibilities for a range of different activities. These possibilities are then discussed in relation to the expectations, conflicts and matters of concern they generate. The discussion revolves around how a certain culture of ethics (La Cecla \& Zanini, 2013), or an ethicality (Puig de la Bellacasa, 2017), has formed itself around blue-green infrastructure. In the text, we refer to stormwater facilities as bluegreen solutions. This concept has recently increased in use in Sweden, both in research and practice, and also makes clear that the two main components we are dealing with here are water and greenery.

\subsection{Affordance Theory}

In this study, we use affordance theory. Affordance theory gives us a relational understanding of how actions can occur in an environment. The psychologist James Gibson introduced the notion of affordance to describe possibilities for action that the environment offers to an actor (Gibson, 1977, 1979). According to him, affordance does not change with the change in perceivers' need. Like the postbox that affords to post letters even when there is no letter to be posted, affordance is permanently present in a certain environment. However, affordances are also relational, which means that they only exist as a relation between specific actors. A certain stone might be suitable to sit on for one person, but not for another. Affordances are also situational (cf. Kopljar, 2016; Nilsson, 2009), they can evolve over time (Heft, 2001) and they can also, as Gaver (1991) has suggested, unfold in a sequential process, i.e., as nested affordances. Gibson was furthermore focused on affordance as part of an ecological psychology and on different patterns of setting-specific actions presenting themselves in the environment to form a kind of ecology of social life (where ecology here must be understood in a broad sense, as the relationships inside and between a complex system and its environment; cf. Heft, 2001, p. 271). Even though affordance theory has often been used in the discussion of individual artefacts and designs (Norman, 1988), a key aspect for Gibson is that affordances relate to environmental concerns. As such, affordance theory might thus readily lend itself to a discussion of more complex milieus and infrastructures such as blue-green infrastructure. However, as has been pointed out by Anique Hommels (2008), infrastructures tend to become stabilised and fixed over time, thus bringing a certain inertia or obduracy to the urban environment. Affordance theory is often used to focus on more direct situations and perceptions, on what is (indisputably) present in the world. However, the theory is perhaps less strong when it comes to investigating disputes, so we need to find another way of engaging with these issues - which leads us to the notion matters of concern.

\subsection{Matters of Concern}

Although affordance theory may be used to discuss the particularities of different species (animals, including humans), it follows from its relational perspective that different users might perceive use quite differently. Thus, different meanings evolve around the same incident or the same space (Dinnie, Brown, \& Morris, 2013). People are concerned about different things. In her book Matters of Care, Puig de la Bellacasa (2017) has elaborated on the ethical as a more-than-human construct (Puig de la Bellacasa, 2017). Here, she does not focus much on ethical norms or obligations, but on how ethical issues are constructed, for example around socio-technological practices, such as soil production and permaculture, and how they play a part in forming an ethicality. Ethics are, as she suggests, "born out of material constraints and situated rationalities in the making" (Puig de la Bellacasa, 2017 , p. 145). She also brings up the notion of 'matters of concern,' which was introduced by Bruno Latour (1999, 2004) as a more productive concept for epistemological discussions than matters of fact. Instead of talking about matters of fact, i.e., of things as indisputably present in the world, Latour argues that we need to acknowledge that things are disputable; they are produced (and reproduced) through different kinds of concerns. Puig de la Bellacasa tries to further investigate the affective and ethico-political aspects of these matters of concerns through developing the concept 'matters of care' (Puig de la Bellacasa, 2011, 2017). Ethics is here seen as entangled in the production of politics and the effects of everyday life, and it can also be seen as something that takes form and stabilises over time. Concerning this temporal dimension, La Cecla and Zanini talk about 'conformity' as two entities that are taking form together, describing conformity as "the almost dance-like ability to put our body next to other bodies without bumping into them or actually dancing with them" (La Cecla \& Zanini, 2013, p. 60). They regard ethics as a form-taking process where habits form ways of conduct, for example, concerning a certain new technology (discussing the introduction of the cell phone into everyday life; La Cecla \& Zanini, 2013, pp. 76-79). We propose that new affordances are also produced through a process of conformity. Affordances take form as the environment becomes a matter of concern and care, which in turn makes these concerns take form and stabilise. With the introduction of blue-green solutions, one would expect new affordances, new concerns and a changing culture of ethics related to the area. In the following, we will look at how the changing landscape of affordances affects and takes part in forming these concerns and vice versa. 


\section{Studying Augustenborg Blue-Green Solutions}

\subsection{Description of Setting}

Our case study is the Augustenborg residential neighbourhood in Malmö. Malmö is the third-largest city in Sweden. In the late 1980s, its fundamental industries failed and the city faced an economic crisis. Since then, Malmö has been undergoing a transition from an industrial to a post-industrial city. This transformation has included neoliberal planning strategies (Baeten, 2012; Pries, 2017) and a re-branding of the city through a new University as well as a focus on sustainability (Holgersen \& Malm, 2015; Lenhart, Bouteligier, Mol, \& Kern, 2014).

Augustenborg is one of the administrative districts of Malmö. According to Statistical data for Malmö (Malmö stad, 2019), updated on 27 September 2019, it is a housing area with 1,887 households. The area has a population of 3,875 inhabitants, and an employment rate of $47 \%$ (for the 20-68 age group). Augustenborg can be considered as an ethnically mixed area, with $41.5 \%$ of inhabitants born in Sweden and $58.5 \%$ born abroad. Augustenborg is entirely owned by the municipal housing company MKB, and it is the first district in the city built according to the guidelines of social housing requirements. The land belonged to Augustenborg and Sofiedal farms, later replaced by Västra Kattarps village in 1805 . The area got different functions and ownership during the time, until it was bought by the city of Malmö in 1911. In 1947, Augustenborg was planned as a post-war housing area. The urban development of Augustenborg aimed at increasing services and recreational values. It was developed from 1948 to 1952 primarily with open 3 - to 5-storey housing blocks. These housing blocks are freely placed, offering a variety of rental apartments except for a few privately owned apartments and single-family houses. The area is characterised by a typical 1940s Swedish architecture with the apartment blocks surrounded by green spaces. There is also a large green park, which is connected to smaller green open spaces (Tykesson \& Ingemark Milos, 2001).

However, social problems such as unemployment, criminality or dissatisfaction with apartments and services formed in the area over time. These problems, together with the national public housing project called the Million Program (Miljonprogrammet) 1965-1974 (Hall \& Vidén, 2005), which provided a higher supply than the demand, increased the number of people moving out of the area in the 1970s. In 1998, the project named Eco City Augustenborg was launched in order to improve the social, economic and ecological conditions of the area. Since urban flooding historically damaged some cellars due to sewage system overflow, mitigating the flood risk was of crucial importance for the project. The project thus also aimed at improving an already green housing area through blue-green solutions (Kazmierczak \& Carter, 2010; Stahre, 2008). The objectives were to manage $70 \%$ to $90 \%$ of the stormwater locally by implementing different kinds of ponds, canals, green roofs and remodelling the park, as well as improving waste management and engaging the community in the development process (Delshammar, Huisman, \& Kristoffersson, 2004; Kazmierczak \& Carter, 2010). The project was quite successful in reducing flooded surfaces during extreme rains, resulting in less flood damage in the area (Sörensen \& Emilsson, 2019). Although there is not enough evidence of socio-economic improvement in the area, some positive social influences have been noticed, such as an improved sense of community (Xu, 2011).

\subsection{Method}

The data for this article was collected from an extensive questionnaire. Following previous research on how blue-green solutions possibly benefit society via additional values (i.e., Lamond \& Everett, 2019; Moore \& Hunt, 2012), the questionnaire was designed to collect information on what blue-green solutions meant to people in Augustenborg. The questionnaire aimed at investigating the interaction between blue-green solutions and urban life in public open spaces. It was designed based on previous observations and studies the research team reviewed, to understand how the respondents interact with different types of blue-green solutions in the neighbourhood. The questionnaire was inspired by affordance theory, and it included sections related to proximity, use and experience around three types of blue-green solutions: a sunken lawn area, wet ponds and paved canals (Figure 2). Respondents were asked to rate different statements regarding these different solutions on 5-point and 7-point Likert scales. Moreover, it contained questions about willingness to pay for blue-green solutions, expectations, stormwater knowledge and demographic information. At the end of each section, some open-ended questions were asked. The questionnaire was distributed to all households in the neighbourhood in November 2018. The filled-in questionnaires were collected by the end of December 2018, answered by 328 respondents (households).

The main object of the questionnaire was to study the affordance of blue-green solutions per se. However, reviewing the respondents' answers uncovered that certain concerns and thoughts have been shaped around blue-green solutions, which obviously affects use and everyday ethics. The descriptive answers opened up perspectives of interaction between people and their environment, which were not noticeable through answers to the designed items. Hence, the materials to be discussed in this article mainly come from the free-text answers (by 222 respondents) to four open-ended questions:

1) In which situation do you encounter this area [shown through illustration]? 'I go there to...'

2) How do you experience this place? 'I like that/I do not like that...' 

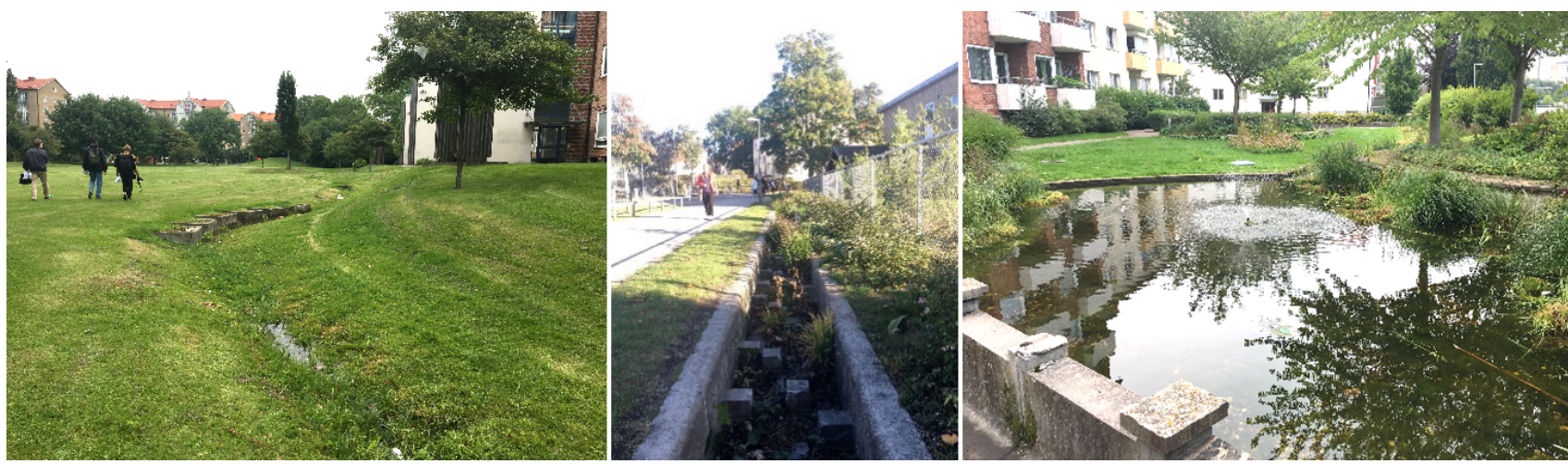

Figure 2. From left to right: Sunken lawn (part of Augustenborg remodelled park); one of the paved canals; one of the wet ponds. Source: Misagh Mottaghi.

3) What would be your suggestions for improving blue-green solutions? If the space should be used for other purposes, please name them.

4) If you have any thought, suggestion or critique on the questionnaire or/and blue-green areas, please share them with us.

The open-ended questions required descriptive answers from the respondent. The questions were asked in order to complement the answers to the Likert scale items.

\section{Affording Concerns: Investigation and Findings}

In this article, we are interested in the affordances that blue-green solutions bring to the neighbourhood and subsequently also how people perceive and care for the affordances. Affordances can be generated over time and new affordances can evolve as we get to know the place better. According to the survey, among 320 respondents who answered the question how long a time they have been living in Augustenborg, 71\% answered five years or more and only $14 \%$ replied two years or less. Table 1 shows the frequency of activities that respondents reported performing around at least one of the blue-green solutions.

The free-text answers provided a more detailed view of the reasons and motives that brought people to these places. From analysing these answers about respondents' individual reflection on what blue-green solutions bring that make the areas different from other green urban spaces, four kinds of affordances were identified. These affordances were produced through interactions between different actors and the environment, and here we have focused on those relations that can be associated with the blue-green solutions (Figure 3). We identified: 1) Affordances related to animals (faunal affordances), based on human-animal and/or their habitat relations; 2) affordances related to other people (social affordances), based on human-human relations; 3 ) affordances related to water (blue affordances), based on human-water relations; and 4) affordances related to synergies (synergistic affordances), based on the compositional relations of human-nonhuman actors and affordances, where the composition not only adds new affordances but transforms them.

The affordances brought certain concerns, expectations and in some cases raised conflicts (created and/or solved conflicts). As mentioned previously, the focus of this article is not on what blue-green solutions afforded as such but on how the affordances, related to the bluegreen solutions, may become a matter of concern. Bluegreen solutions brought affordances that shift people's concerns and cares, and blue-green solutions might thus be seen as playing a part in the shaping of a new ethicality.

Table 1. Frequency of activities the respondents do close to at least one of the blue-green solutions.

\begin{tabular}{|c|c|c|c|c|c|c|}
\hline & $\begin{array}{l}\text { Number of } \\
\text { respondents } \\
\text { (n) }\end{array}$ & $\begin{array}{l}\mathrm{n}(\%) \\
\text { Never }\end{array}$ & $\begin{array}{c}n(\%) \\
\text { A few times } \\
\text { a year }\end{array}$ & $\begin{array}{c}\mathrm{n}(\%) \\
\text { A few times } \\
\text { a month }\end{array}$ & $\begin{array}{c}\mathrm{n}(\%) \\
\text { A few times } \\
\text { a week }\end{array}$ & $\begin{array}{c}\mathrm{n}(\%) \\
\text { Everyday }\end{array}$ \\
\hline $\begin{array}{l}\text { I go there to walk, bike, run, } \\
\text { jog or dog walk. }\end{array}$ & 325 & 2 & 2 & 4 & 22 & 70 \\
\hline $\begin{array}{l}\text { I go there to sit for a while, } \\
\text { look around/think/spend } \\
\text { time, talk to/hang out with } \\
\text { others, play games/play/do } \\
\text { sports or read. }\end{array}$ & 319 & 16 & 17 & 18 & 27 & 22 \\
\hline
\end{tabular}




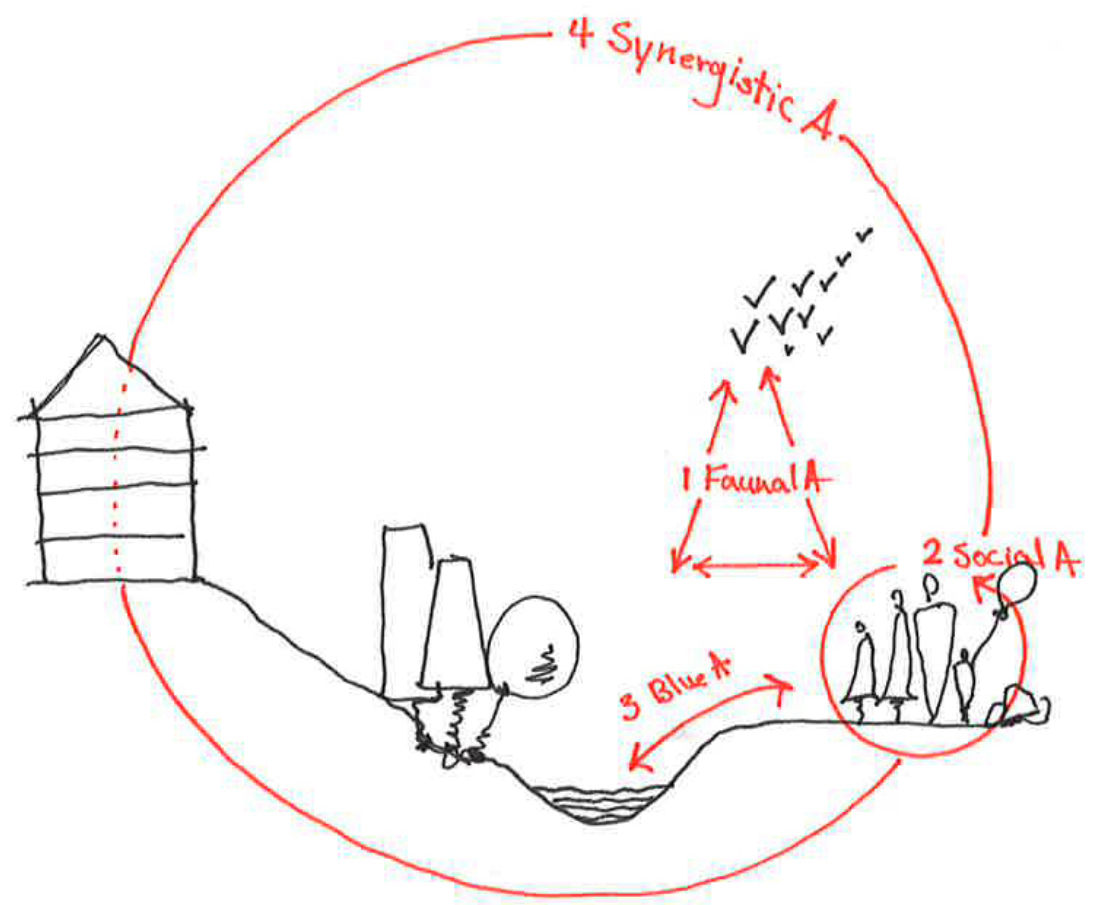

Figure 3. Four kinds of Affordance around blue-green solutions in Augustenborg, Malmö. Notes: 1) Faunal affordance, related to nonhuman animals; 2 ) social affordance, related to the presence of other people; 3 ) blue affordance, related to water; and 4) synergistic affordance, related to synergy. These affordances were identified from respondents' comments, and we focused especially on the affordances that cannot easily be applied to green spaces without blue-green solutions. Source: Misagh Mottaghi.

\subsection{Concerns around Faunal Affordances}

Animals usually go to places where they have access to food and water. Green spaces generally allow wildlife to thrive as they provide animals with shelter and food. Due to the presence of water, blue-green solutions might attract more animals and of more various species than an ordinary urban green area. This creates crowding of not only animals but also of people interested in animals. Blue-green solutions afford being close to animals, which also was seen as a positive experience by many of the respondents. The presence of animals mediates a specific kind of human interaction, the blue-green solutions seem to be strengthening the relations between humans and animals in everyday life (cf. Holmberg, 2015). People care for animals, like the respondent who complained that "the fish there are not moved out during winter so they die." They also want them to have a good habitat: "Cutting the vegetation is not ok during the seasons when animals have offspring (need to hide)." However, animals are also categorised as pets or vermin, and domestic or wild. People are often selective, for example, they like birds but not rats and insects. They might refer to rats and rodents as more disturbing animals than others, while birds, ducks, rabbits, fish and dogs are regarded as 'nice' animals. Even with animals considered as nice, there is, however, a limit, e.g., people may not want "too many rabbits" in a given area. The special habitat that blue-green solutions generate attracts many species. Controlling the population of some or fragmenting the habitat for different species is difficult. When someone suggests "more ponds for wildlife," it will bring more rats and insects too, which others might hate. The same happens concerning birds "ponds attract rare birds to cities i.e., heron and (through ducklings) eagle and falcon" which are wild and do not get along with domestic ones. On the other hand, the presence of birds might be interesting but not everywhere and not for everyone, like the respondent who noted: "I do not like gulls that are attracted by the water and the green roofs, [they are] disturbing."

People generally expressed their interaction with animals as something enjoyable, i.e., "to watch them" or "to photograph them." However, they did not always approve of other's experiences, such as "when kids chase ducks," or "when people disturb birds," or "feeding birds." Another matter of conflict concerns the fish. While some think that the ponds afford fish to be there for people to enjoy and watch, others might think that the fish are there to feed, or to fish. Facing an unfamiliar animal-related situation, some actions might thus be seen as almost incomprehensible by others. For instance, a respondent referred to a man they had met at the pond who "was trying to chase away the heron because, according to him, it ate the fish." This uncertainty or dissonance on how to address the place and situation 
around blue-green solutions might also be what affords a culture of ethics, or ethicality, to slowly evolve.

\subsection{Concerns around Social Affordances}

By social affordance, we do not necessarily mean social exchanges in general but refer to those possibilities for action that are related to actions that other people or social groups do. This type of affordance can be seen as important for everyday life around blue-green solutions. It relates to the interdependence of subjects and explains how people can influence other people's behaviour through their own interaction. Socio-material concerns might also affect mundane encounters and their power relations in different ways (Amin, 2008; Valentine, 2008). The use is dependent on others and in certain places this might even alter the coexisting of different social groups. For instance, very often the respondents mentioned that they either use one type of bluegreen solutions or like or dislike it because of how other groups of people relate to it.

The respondents' interest in social life was quite varied. One person liked "when there are many people" in the area. Others did not. However, children, the elderly, neighbours, friends, families and relatives were usually referred to as something that attracts people to blue-green solutions. Blue-green solutions were mentioned as gathering spots that afford meeting, talking, playing, mingling, gathering or even watching others as reasons to use the area. Children were stated as a specifically important group in generating life either as the producer of an action, "I like to watch children playing," or the co-producer of action, "I go there to play and walk with my grandchild." Some comments show how the play value of blue-green areas was appreciated as something relating people to their own past, i.e., I go there because "it reminds me of my childhood."

Moreover, the categories of children, elderly and disabled were mentioned in relation to two types of concerns. The first relates to the physical environment. This was regarded as something "different and cool for children," but also as something that mediates risk. For example, canals were sometimes seen as "a bit dangerous for small kids who easily run, roll and hurt themselves," the ponds as "a bit dangerous for small kids who like bathing," or the sunken area might become problematic because of the "gravel since the walker gets stuck and sinks." The second type of concern relates to the social environment, and especially to worries about the interrelation of different social groups, often highlighting negative impacts of other's behaviour: "I do not like when people sit [around ponds] and drink alcohol and argue with one another, the children get scared."

Addicts, criminals, drug dealers, homeless people and motorcyclists were mentioned as groups that repel some from the outdoor environment. There are two perspectives on these groups. The most common one views them as problematic occupiers of space, for example, when calling the area Alkisplats (place of alcoholics), or stating that "criminal gangs, drug addicts and drug dealers need to be evicted, and that it would be worth the higher rent to set up CCTV." A less common viewpoint was that one needs to show some kind of respect for these groups: "Sometimes there are intoxicated people there [around the ponds], but where should they sit? Perhaps more benches [are needed]."

\subsection{Concerns around Blue Affordances}

This group of affordances concerns relations between humans and water. The respondents wrote about different kinds of concerns. Some referred to the special feeling water brings them: "It is wonderfully nice with the ponds and fountains"; I like the fact that the pond is like a "fantastic little lake." Likewise, many statements concern relations people have with water through their senses. For instance, I like "the sound of the water" or it is "aesthetically pleasing with ponds." Hartson (2003) calls it sensory affordance. Some people expressed worries as well, explaining that the water and open canals could be attractive but also dangerous for children.

Imbedding blue-green solutions in Augustenborg's outdoor environment turns the area into a space where urban landscape and urban infrastructure intertwine and thus blurs the distinctions between the operational and non-operational structures (Gandy, 2014). Water not only affords pedagogical possibilities, i.e., "I go there with my grandchild to see how the water flows" but also offers specific greenery. For example, some appreciated the water lilies or "the green area with water." The respondents who knew about the purpose of the bluegreen solutions also referred to how they afford protection from flooding: "I like the way the canals collect water," or "I like the sunken area because it can collect a large amount of rain." However, not everyone agreed on this, like the one who believes "the stormwater installations work bad in rain."

Other types of affordances are those that come and go with temporal shifts, e.g., seasonal change or changes in temperature. "I do not like that children and teenagers destroy [the ice] when the water turns into ice," or, I do not like that "in the summer the water is disgusting green, dirty, muddy." Some people expressed how they liked when it rained, and others how they disliked it. Many of the affordances also created new expectations on the environment. For instance, when someone realised how 'nice' it is to see or be close to water, or how "aesthetically pleasing [it is] with ponds," it becomes unacceptable when "the water is dirty or smells bad." Furthermore, people seemed to relate to stormwater in different ways. Knowing that blue-green solutions are there to collect water, some showed their dissatisfaction with the absence of water. Seeing running water made some people aware of how nice it is to see or hear it. We thus see both quotes about how they like "the running water" or "how nice the water flows," and quotes 
that complain "there is never water" or "there is too little water/running water there."

\subsection{Concerns around Synergistic Affordances}

Synergistic affordances can be described as the outcome of a synergy effect from a composition of different affordances. Recently, Hoelscher and Chatzidakis (2020) have used the term to describe dualistic relations between physical and digital realms, which enhance the usability within both realms. However, by applying the term we here refer to affordance as an outcome effect dependent on how different actors work together, for example, to produce a certain atmosphere (Gandy, 2017) or niche as a "set of affordances" (Gibson, 1979, p. 128), but it also implies that this set of affordances produce something more than just an agglomeration, i.e., a synergy effect. For example, some respondents suggested that more fruit trees are needed around the blue-green solutions. At first, fruit trees may not be directly related to the affordance of the blue-green solutions. Yet, when someone writes, "I would like to see more fruits and berries so when you are out there with kids or animals you can also eat," it means that being there, together with kids or pets, and together with fruit trees, the place affords you to do more and stay longer. It also affords you to experience something different, as it generates other types of affordances (such as attracting more animals and people) interacting with you, and perhaps enhancing the quality of your experience.

Another example, also related to social affordance, is the presence of 'regulars.' As mentioned before, alcoholics were named as a group whose presence the respondents did not usually appreciate. However, interestingly, this group was mentioned mostly when it comes to the ponds. Perhaps this only shows that the ponds are the most attractive, but it might also indicate that different blue-green solutions might attract different groups of people, or that different types of composition may affect specific groups differently.

The last example of synergistic affordance relates to maintenance. Out of the 222 respondents who answered the free-text questions, around 90 made maintenancerelated comments. Here, only a few showed satisfaction, whereas the majority made complaints. These complaints often showed the importance of taking care of blue-green solutions when it comes to everyday use. For instance, it was mentioned that "ponds that are full of trash and dirt smell bad, and instead of thinking about how nice the water is, you do not even want to pass by it." Some comments described how people who use the outdoor environment neglected their responsibility to take care of the area: "Since the blue-green surfaces are so littered, it is difficult to appreciate one's time there." Other comments complained about maintenance more generally: "Since the ponds are handled so poorly, the water stands still. Then algae form toxic algae. The rats can roam there freely." Another informant noted that "some ponds are not kept clean. They are dirty and it is not possible to see the fishes."

What makes a certain blue-green solution pleasurable or not is the outcome of the interaction of different actors such as property owners, users of the environment, designs, animals, greenery, water, seasonal changes, etc. This does of course not mean that bluegreen solutions, more than other green areas, afford to throw trash or maintenance to be ignored, but it might highlight the fact that blue-green environments are especially sensitive to this. Blue-green solutions, with their sometimes-empty ponds, etc., have the potential to turn certain spaces into displays. Also, since blue-green solutions might attract more people than an average green area, it might be especially important that these areas are equipped with more different kinds of furniture, such as wastebaskets and barbecue areas. Some statements indicate that blue-green solutions afford trash to be gathered in specific locations. Since the trash can travel with water, depending on the amount of rain, the design of blue-green solutions, etc., trash gathers in some spots, becomes more noticeable and demands more maintenance. Here there are, however, also potential conflicts, as some people are dissatisfied with the machines used for the cleaning and trimming of plants. For example, one person wrote that s/he did not like "the leaf blower, lawn mower (machines) that make noise." Machines do not only cause disturbing sounds but as mentioned before, cutting the bushes might alter the required environment for animals to nest or hide. Moreover, due to the microclimate and the presence of water, the greenery might grow differently and also produce more biological waste, which makes it difficult to afford good maintenance and to mediate between different expectations. It became very clear, through the answers, that the respondents had very different and sometimes conflicting views on nature. Some people wanted nature to be wild, whereas others preferred it well-maintained.

\section{Conclusion}

Blue-green solutions introduce a large number of affordances that do not only concern the taking care of stormwater. In the case of Augustenborg, they especially concerned what we have called faunal, social, blue and synergistic affordances. The new urban designs and materialities thus played a part in new forms of social conduct and care, including caring for certain animals, children and for maintenance, but also raised concerns with weeds, litter, rats, and the configuration of social groups. Different non-human actors constantly influence human interactions (Latour, 2005). Through our case study, it became clear that an ecology of affordances (or a niche) is also related to a political ecology and to concerns around what actors (humans as well as non-humans) can use the place and how they can do so (Latour, 2005). Furthermore, it is an ecology of care where people and animals are affected and where new 
routines and mechanisms need to be formed for what should be cared for and what should not.

From our study of Augustenborg, it became clear that the introduction of blue-green solutions was not just the addition of another technology, but that it takes part in a territorial transformation and in the production of a new sort of place, which also comes with new expectations. In a way, the environment becomes open to new interpretations and ways of behaviour. Affordance often makes for a strong justification of certain actions, since they easily lend themselves to pleas based on analogies to 'the natural' (Douglas, 1986, p. 46). Affordances are, however, not just there to be 'found' but they are produced as socio-material relations. What we see in this case is how the production of affordances also comes with the conformation (La Cecla \& Zanini, 2013) of an ethicality, taking part in shaping the behaviour of people but also shaping the territory itself. Augustenborg's bluegreen area affords new kinds of crowds to gather (of both humans and animals), and these, in turn, produce new affordances (e.g., synergistic ones). Augustenborg gets a new intensity that leads to a reterritorialisation and densification of the area. New uses, species and groups find their place, old relations are broken and new ones are formed.

In this case, the densification of actors (human and non-human) also means that the place becomes a matter of concern for more people and animals, and new negotiations proliferate in its wake. The introduction of a certain technological infrastructure like blue-green infrastructure, might at first look innocent, but it brings much more than meets the eye. It is an object that can take on many different actor roles, a niche that allows for new kinds of relations to evolve, and once introduced, stormwater is far from the only concern that this technology needs to deal with. The introduction of blue-green solutions brings about new affordances, but also new kinds of sensitivities and new senses of care. It adds qualities and possibilities, and this, in turn, brings an intensification or a compression of related concerns. These concerns have important social repercussions as they might affect power relations and questions of who can do what, where and how. As the implementation of blue-green solutions is also focused to already existing urban settings, a social intensification and/or compression might potentially be problematic.

We have only looked at one case in this article, but our findings point to the importance of studying the social role and implications of this new technology in future studies. With an affordance perspective, it became possible to see how new designs aiming at bionomic concerns also stirred up a series of socio-material concerns that subsequently needed to be negotiated and settled. We think that an ecological perspective (in the sense of focusing on systems of relations), coupling affordances with matters of concern and care, might be a fruitful way to study the effects of new urban planning implementations in the future-especially for those interest- ed in the relationship between urban design, on the one hand, and the forming of ethicalities in everyday life, on the other. The ecological perspective cannot be reduced to questions of 'ecological sustainability,' but is just as needed when we study the social effects of urban planning and design.

\section{Acknowledgments}

This article was supported by Sweden Water Research $A B$ and Formas grant 2017-01943 'Urban Design and Everyday Life Choices: On the Built Environment as a Co-Producer of Climate Ethics.' We acknowledge the MKB housing company for assisting us in distributing and collecting the questionnaires. Special thanks are extended to the inhabitants of Augustenborg for contributing with their valuable insights.

\section{Conflict of Interests}

The authors declare no conflict of interests.

\section{References}

Amin, A. (2008). Collective culture and urban public space. City, 12(1), 5-24.

Ashley, R., Gersonius, B., Digman, C., Horton, B., Bacchin, T., Smith, B., .. Baylis, A. (2018). Demonstrating and monetizing the multiple benefits from using SuDS. Journal of Sustainable Water in the Built Environment, 4(2). https://doi.org/10.1061/JSWBAY.0000848

Ashley, R., Gersonius, B., \& Horton, B. (2020). Managing flooding: From a problem to an opportunity. Philosophical Transactions of the Royal Society A: Mathematical, Physical and Engineering Sciences, 378. https://doi.org/10.1098/rsta.2019.0214

Bacchin, T. K. (2015). Performative nature: Urban landscape infrastructure design in water sensitive cities (Unpublished Doctoral dissertation). TU Delft, Delft, the Netherlands.

Backhaus, A., \& Fryd, O. (2013). The aesthetic performance of urban landscape-based stormwater management systems: A review of twenty projects in Northern Europe. Journal of Landscape Architecture, 8(2), 52-63.

Baeten, G. (2012). Normalising neoliberal planning: The case of Malmö, Sweden. In T. Tasan-Kok \& G. Baeten (Eds.), Contradictions of neoliberal planning (pp. 21-42). Dordrecht: Springer.

Chocat, B., Krebs, P., Marsalek, J., Rauch, W., \& Schilling, W. (2001). Urban drainage redefined: From stormwater removal to integrated management. Water Science and Technology: A Journal of the International Association on Water Pollution Research, 43(5), 61-68.

Delshammar, T., Huisman, M., \& Kristoffersson, A. (2004). Uppfattningar om öppen dagvattenhantering i Augustenborg, Malmö [Perceptions of open 
stormwater management in Augustenborg, Malmö]. SMHI. Retrieved from https://www.smhi.se/klimat/ klimatanpassa-samhallet/exempel-pa-

klimatanpassning/oppen-dagvattenhanteringi-malmostadsdelen-augustenborg-fordjupning1.115721

Dinnie, E., Brown, K. M., \& Morris, S. (2013). Reprint of community, cooperation and conflict: Negotiating the social well-being benefits of urban greenspace experiences. Landscape and Urban Planning, 118, 103-111.

Douglas, M. (1986). How institutions think. Syracuse, NY: Syracuse University Press.

Fletcher, T. D., Shuster, W., Hunt, W. F., Ashley, R., Butler, D., Arthur, S., . . . Viklander, M. (2015). SUDS, LID, BMPs, WSUD and more: The evolution and application of terminology surrounding urban drainage. Urban Water Journal, 12(7), 525-542.

Gandy, M. (2014). The fabric of space: Eater, modernity, and the urban imagination. Boston, MA: The MIT Press.

Gandy, M. (2017). Urban atmospheres. Cultural Geographies, 24(3), 353-374.

Gaver, W. W. (1991). Technology affordances. Paper presented at the SIGCHI Conference on Human Factors in Computing Systems, New Orleans, LA. https://doi. org/10.1145/108844.108856

Gibson, J. J. (1977). "The theory of affordances," in perceiving, acting, and knowing: Towards an ecological psychology. Hoboken, NJ: John Wiley \& Sons Inc.

Gibson, J. J. (1979). The ecological approach to visual perception. Boston, MA: Houghton Mifflin.

Haghighatafshar, S. (2019). Blue-green stormwater systems for citywide flood mitigation: Monitoring, conceptualization, modeling, and evaluation. Lund: Department of Chemical Engineering, Faculty of Engineering of Lund University.

Hall, T., \& Vidén, S. (2005). The million homes programme: A review of the great Swedish planning project. Planning Perspectives, 20(3), 301-328.

Hartson, H. R. (2003). Cognitive, physical, sensory, and functional affordances in interaction design. Behaviour \& Information Technology, 22(5), 315-338.

Heft, H. (2001). Ecological psychology in context: James Gibson, Roger Barker, and the legacy of William James's radical empiricism. Mahwah, NJ: Psychology Press.

Hoelscher, V., \& Chatzidakis, A. (2020). Ethical consumption communities across physical and digital spaces: An exploration of their complementary and synergistic affordances. Journal of Business Ethics. https:// doi.org/10.1007/s10551-020-04477-6

Holgersen, S., \& Malm, A. (2015). "Green fix" as crisis management; or, in which world is Malmö the world's greenest city? Geografiska Annaler Series B: Human Geography, 97(4), 275-290.

Holmberg, T. (2015). Urban animals: Crowding in zoocities. Abingdon: Routledge.
Hommels, A. (2008). Unbuilding cities: Obduracy in urban sociotechnical change. Boston, MA: MIT Press.

Intergovernmental Panel on Climate Change. (2014). Climate change 2014 synthesis report: Contribution of working groups I, II and III to the fifth assessment report of the Intergovernmental Panel on Climate Change. Geneva: IPCC.

Kazmierczak, A., \& Carter, J. (2010). Adaptation to climate change using green and blue infrastructure. $A$ database of case studies. Brussels: The European Climate Adaptation Platform Climate.

Kazmierczak, A., \& Cavan, G. (2011). Surface water flooding risk to urban communities: Analysis of vulnerability, hazard and exposure. Landscape and Urban Planning, 103(2), 185-197. https://doi.org/10.1016/ j.landurbplan.2011.07.008

Kopljar, S. (2016). How to think about a place not yet: Studies of affordance and site-based methods for the exploration of design professionals' expectations in urban development processes: Lund: Department of Architecture and the Built Environment, Faculty of Engineering of Lund University.

La Cecla, F., \& Zanini, P. (2013). The culture of ethics. Cambridge: Prickly Paradigm.

Lamond, J., \& Everett, G. (2019). Sustainable blue-green infrastructure: A social practice approach to understanding community preferences and stewardship. Landscape and Urban Planning, 191. https://doi.org/ 10.1016/j.landurbplan.2019.103639

Latour, B. (1999). Pandora's hope: Essays on the reality of science studies. Cambridge, MA: Harvard University Press.

Latour, B. (2004). Politics of nature. Cambridge, MA: Harvard University Press.

Latour, B. (2005). Reassembling the social: An introduction to actor-network-theory. Cambridge, MA: Harvard University Press.

Lenhart, J., Bouteligier, S., Mol, A. P. J., \& Kern, K. (2014). Cities as learning organisations in climate policy: The case of Malmö. International Journal of Urban Sustainable Development, 6(1), 89-106.

Malmö stad. (2019). Statistik för Malmös områden [Statistics of Malmö urban areas]. Malmö stad. Retrieved from https://malmo.se/Fakta-ochstatistik/Statistik-for-Malmos-omraden.html

Moore, T. L. C., \& Hunt, W. F. (2012). Ecosystem service provision by stormwater wetlands and ponds: A means for evaluation? Water Research, 46(20), 6811-6823. https://doi.org/10.1016/j.watres.2011. 11.026

Mottaghi, M., Aspegren, H., \& Jönsson, K. (2016). Integrated urban design and open storm drainage in our urban environments: Merging drainage techniques into our city's urban spaces. Water Practice and Technology, 11(1), 118-126.

Nilsson, D. (2009). Exit choice in fire emergencies: Influencing choice of exit with flashing lights. Lund: Department of Fire Safety Engineering and Systems 
Safety of Lund University.

Norman, D. A. (1988). The psychology of everyday things. New York, NY: Basic Books.

Pries, J. (2017). Social neoliberalism through urban planning: Bureaucratic formations and contradictions in Malmö since 1985. Lund: Lund University.

Puig de la Bellacasa, M. (2011). Matters of care in technoscience: Assembling neglected things. Social Studies of Science, 41(1), 85-106.

Puig de la Bellacasa, M. (2017). Matters of care: Speculative ethics in more than human worlds. Minneapolis, MN: University of Minnesota Press.

Radhakrishnan, M., Pathirana, A., Ashley, R. M., Gersonius, B., \& Zevenbergen, C. (2018). Flexible adaptation planning for water sensitive cities. Cities, 78, 87-95. https://doi.org/10.1016/j.cities.2018.01.022

Sörensen, J., \& Emilsson, T. (2019). Evaluating flood risk reduction by urban blue-green infrastructure using insurance data. Journal of Water Resources Planning and Management, 145(2). https://doi.org/10.1061/ (ASCE)WR.1943-5452.0001037

Stahre, P. (2008). Blue-green fingerprints in the city of Malmö, Sweden: Malmö's way towards a sustainable urban drainage. Malmö: VA Syd.
Stovin, V., \& Ashley, R. (2019). SuDS/BMPs/WSUD/SCMs: Convergence to a blue-green infrastructure. Urban Water Journal, 16(6). https://doi.org/10.1080/ 1573062X.2019.1685229

Tykesson, T. L., \& Ingemark Milos, A. (2001). Bostadsmiljöer i Malmö: inventering. D. 1 1945-1955 [Residential areas in Malmö: An inventory, P. 1 19451955]. Malmö: Malmö kulturmiljö.

United Nations. (2019). World urbanization prospects: The 2018 revision (ST/ESA/SER.A/420). New York, NY: United Nations.

Valentine, G. (2008). Living with difference: Reflections on geographies of encounter. Progress in Human Geography, 32(3), 323-337.

Vierikko, K., \& Niemelä, J. (2016). Bottom-up thinking: Identifying socio-cultural values of ecosystem services in local blue-green infrastructure planning in Helsinki, Finland. Land Use Policy, 50, 537-547. https://doi.org/10.1016/j.landusepol.2015.09.031

$\mathrm{Xu}, \mathrm{Y}$. (2011). Augustenborg: A sustainable community assessment: Considering the sense of community (Unpublished Master dissertation). Uppsala University, Uppsala, Sweden.

\section{About the Authors}

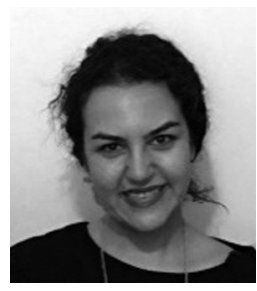

Misagh Mottaghi is a PhD Student of Architecture at Lund University, Sweden. She is conducting research for Sweden Water Research and her research deals with blue-green infrastructure, focusing on how blue-green solutions affect the quality of public spaces in relation to everyday life.

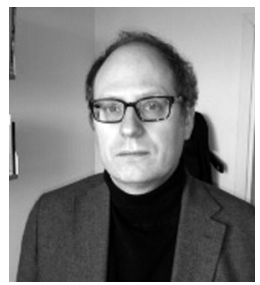

Mattias Kärrholm a Professor of Architectural Theory at Lund University, Sweden. His research deals with territoriality, public space, building types, space and culture, and everyday life. He has written the book Retailising Space (2012, now on Routledge), and together with Andrea Mubi Brighenti the book Animated Lands, Studies in Territoriology (2020, Nebraska University Press).

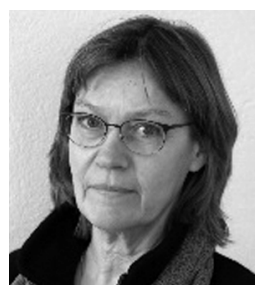

Catharina Sternudd is Senior Lecturer of Architecture and Head of Department of Architecture and Built Environment at Faculty of Engineering, Lund University, Sweden. She is also a Coordinator of Urban Arena, a platform that gathers research on sustainable urban development at Lund University. Her research revolves around urban design with a special focus on environmental support for sustainable everyday practices, such as walking and children's independent psychical activity. 